\title{
Behavioral effects of "vehicle" microinjected into the dorsal periaqueductal grey of rats tested in the elevated plus maze
}

M.G. Matheus,

J.C. de-Lacerda and F.S. Guimarães

\author{
Departamento de Farmacologia, Faculdade de Medicina de Ribeirão Preto, \\ Universidade de São Paulo, 14049-900 Ribeirão Preto, SP, Brasil
}

\section{Correspondence \\ F.S. Guimarães \\ Departamento de Farmacologia \\ FMRP, Campus USP \\ 14049-900 Ribeirão Preto, SP \\ Brasil \\ Fax: 55 (016) 633-2301 \\ E-mail: fsguimar@fmrp.usp.br \\ Research supported by FAPESP and CNPq.}

Received April 16, 1996 Accepted October 21, 1996

\begin{abstract}
To investigate the behavioral effects of different vehicles microinjected into the dorsal periaqueductal grey (DPAG) of male Wistar rats, weighing 200-250 g, tested in the elevated plus maze, animals were implanted with cannulas aimed at this structure. One week after surgery the animals received microinjections into the DPAG of $0.9 \%$ (w/v) saline, $10 \%(\mathrm{v} / \mathrm{v})$ dimethyl sulfoxide (DMSO), $2 \%(\mathrm{v} / \mathrm{v})$ Tween$80,10 \%(\mathrm{v} / \mathrm{v})$ propylene glycol, or synthetic cerebrospinal fluid (CSF). Ten min after the injection $(0.5 \mu \mathrm{l})$ the animals $(\mathrm{N}=8-13 /$ group) were submitted to the elevated plus maze test. DMSO significantly increased the number of entries into both the open and enclosed arms when compared to $0.9 \%$ saline $(2.7 \pm 0.8$ and $8.7 \pm 1.3$ vs $0.8 \pm$ 0.3 and $5.1 \pm 0.9$, respectively, Duncan test, $\mathrm{P}<0.05$ ), and tended to increase enclosed arm entries as compared to $2 \%$ Tween- $80(8.7 \pm 1.3$ vs $5.7 \pm 0.9$, Duncan test, $\mathrm{P}<0.10$ ). In a second experiment no difference in plus maze exploration was found between $0.9 \%$ salineor sham-injected animals ( $N=11-13 /$ group). These results indicate that intra-DPAG injection of some commonly used vehicles such as DMSO, saline or Tween- 80 affects the exploratory activity of rats exposed to the elevated plus maze in statistically different manners.
\end{abstract}

Key words

- Elevated plus maze

- Vehicles

- Periaqueductal grey

- Dimethyl sulfoxide
The dorsal midbrain periaqueductal central grey (DPAG) is part of a neural system that includes the amygdala and the medial hypothalamus and is responsible for the expression of aversive/defensive behaviors (1). The neurochemistry of this region has been investigated using several approaches. Employing intra-DPAG drug microinjections we and others have shown that GABA/benzodiazepine, glutamate, serotonin and opioid receptors modulate the behavior of rats submitted to the elevated plus maze, a widely used animal model of anxiety (1-3). For more than a century intracerebral injections of drugs have been used to investigate the central effects of psychotropic compounds (4). Not all compounds, however, are easily dissolved in water or saline. Solvents such as Tween80, propylene glycol or dimethyl sulfoxide (DMSO) are often used as vehicles for intracerebral drug administration $(3,5)$ and some have been used in experiments involving the DPAG (3). Few studies have investigated the possible effects of these compounds on be- 
havior (6). The objective of the present study was to determine the effects of these vehicles when microinjected into the dorsal periaqueductal grey of rats tested in the elevated plus maze.

Male Wistar rats weighing 200-250 g were housed in groups of 6 for two days before surgery and in pairs thereafter, with free access to food and water in a temperature-controlled room $\left(23 \pm 1^{\circ} \mathrm{C}\right)$ under a $12 /$ $12 \mathrm{~h}$ light/dark cycle (lights on at 6:30 a.m.). The rats were anesthetized with $2.5 \% 2,2,2,-$ tribromoethanol $(10 \mathrm{ml} / \mathrm{kg}$, ip $)$ and submitted to stereotactic surgery to implant a stainless steel guide cannula ( $0.7 \mathrm{~mm}$ OD) aimed at the DPAG (coordinates: $1.9 \mathrm{~mm}$ lateral to the right side of lambda at an angle of $22^{\circ}$ with the sagittal plane; Ref. 7). The cannula tip was $4.0 \mathrm{~mm}$ below the surface of the skull and was attached to the bones with stainless steel screws and acrylic cement. A stylet was introduced into the guide cannula to prevent obstruction.

The wood plus-shaped maze consisted of two opposite open arms $(50 \times 10 \mathrm{~cm})$ crossed at right angles by two arms of the same dimensions and enclosed by $40-\mathrm{cm}$ high walls with no roof. The maze was located $50 \mathrm{~cm}$ above the floor and a 1-cm high edge made of plexiglas surrounded the open arms to prevent falls.

The experiment was carried out in a sound-attenuated and temperature-controlled $\left(23 \pm 1^{\circ} \mathrm{C}\right)$ room, illuminated with two $40-\mathrm{W}$ fluorescent lights placed $1.3 \mathrm{~m}$ away from the elevated plus maze. The observer sat in the same room at a distance of $1 \mathrm{~m}$ from the maze. The following vehicles were used: $0.9 \%(\mathrm{w} / \mathrm{v})$ sterile saline, synthetic cerebrospinal fluid (CSF), $10 \%$ (v/v) DMSO, $2 \%$ (v/v) Tween- 80 or $10 \%(\mathrm{v} / \mathrm{v})$ propylene glycol. CSF had the following composition: 138.6 $\mathrm{mM} \mathrm{NaCl}, 3.33 \mathrm{mM} \mathrm{KCl}, 0.95 \mathrm{mM} \mathrm{CaCl}_{2}$, $0.54 \mathrm{mM} \mathrm{MgCl}_{2}$, and $11.9 \mathrm{mM} \mathrm{NaHCO}_{3}$ (8).

Seven days after surgery the animals were assigned randomly to one of the groups. Intracerebral injections were performed with a thin dental needle $(0.3 \mathrm{~mm}$ OD) introduced through the guide cannula until its tip was 1 $\mathrm{mm}$ below the cannula end. A volume of 0.5 $\mu \mathrm{l}$ was injected over a period of $30 \mathrm{sec}$ using a Hamilton microsyringe (3). The needle was left inside the guide cannula for an additional 30 -sec period to avoid reflux. After $10 \mathrm{~min}$ the animal was placed in the center of the plus maze facing an enclosed arm. The number of entries into and time spent in open and enclosed arms were recorded for $5 \mathrm{~min}$. After each trial the maze was cleaned with a 70\% alcohol solution. In a second experiment we compared animals injected with $0.9 \%(\mathrm{w} / \mathrm{v})$ sterile saline $(0.5$ $\mu l)$ with those that had the dental needle introduced into the guide cannula as described above, but did not receive any injection (sham injected). All groups were run in parallel in each experiment. Histological localization of the injection sites was performed after the behavioral test (3). Data for animals with injection sites outside the DPAG were excluded from analysis. The number of entries and the time spent in the open or enclosed arms, as well as the percent of open arm entries (100 x open/total entries) and of time spent in the open arms (100 x open/ open + enclosed) were analyzed by one-way analysis of variance (ANOVA) followed by the Duncan test for multiple comparisons, or by the Student $t$-test, as indicated.

No significant difference in the time spent in open or enclosed arms, or in the percentage of entries or time spent in open arms (Duncan test, $\mathrm{P}>0.05$ ) was observed in experiment 1. DMSO $(10 \%, \mathrm{v} / \mathrm{v})$, however, significantly increased the number of entries into open $(\mathrm{F} 4,48=1.52, \mathrm{P}=0.2$, Duncan test, $\mathrm{P}<0.05)$ or enclosed arms ( F4,44 = 1.91, $\mathrm{P}=0.12$, Duncan test, $\mathrm{P}<0.05)$ compared to saline. DMSO $(10 \%, \mathrm{v} / \mathrm{v})$ also tended to increase the total number of entries as compared to Tween-80 (Duncan test, $\mathrm{P}<0.10$, Table 1). No difference was found between $0.9 \%$ saline- or sham-injected animals (Duncan test, $\mathrm{P}>0.05$, Table 2). 
Table 1 - Behavioral effects of vehicles microinjected into the dorsal periaqueductal grey of rats tested in the elevated plus maze.

Data are reported as means \pm SEM. ${ }^{*} P<0.05$ and ${ }^{+} P<0.10$ compared to the group injected with $10 \%$ dimethyl sulfoxide (Duncan test).

\begin{tabular}{lccccc}
\hline & $\begin{array}{c}0.9 \% \text { Saline } \\
(\mathrm{N}=10)\end{array}$ & $\begin{array}{c}\text { 10\% Dimethyl } \\
\text { sulfoxide }(\mathrm{N}=8)\end{array}$ & $\begin{array}{c}10 \% \text { Propylene } \\
\text { glycol (N = 8) }\end{array}$ & $\begin{array}{c}\text { 2\% Tween-80 } \\
(\mathrm{N}=13)\end{array}$ & $\begin{array}{r}\text { Cerebrospinal } \\
\text { fluid (N = 10) }\end{array}$ \\
\hline \% Open/total entries & $9.8 \pm 3.7$ & $21.1 \pm 5.4$ & $14.9 \pm 4.0$ & $18.2 \pm 3.8$ & $16.4 \pm 4.5$ \\
\% Open/total time spent & $3.5 \pm 1.6$ & $9.8 \pm 3.2$ & $7.2 \pm 3.4$ & $7.1 \pm 2.7$ & $7.9 \pm 2.8$ \\
Number of open arm entries & $0.8 \pm 0.3^{*}$ & $2.8 \pm 0.8$ & $1.9 \pm 0.7$ & $1.6 \pm 0.5$ & $1.6 \pm 0.5$ \\
Number of enclosed arm entries & $5.1 \pm 0.9^{*}$ & $8.7 \pm 1.3$ & $8.0 \pm 1.5$ & $5.6 \pm 0.9^{+}$ & $7.3 \pm 0.9$ \\
Time in open arms & $8.6 \pm 3.9$ & $23.9 \pm 7.5$ & $17.5 \pm 8.2$ & $15.4 \pm 4.6$ & $19.1 \pm 6.8$ \\
Time in enclosed arms & $255.1 \pm 10.6$ & $229.9 \pm 12.8$ & $237.8 \pm 14.4$ & $245.3 \pm 15.6$ & $232.1 \pm 11.6$
\end{tabular}

Sterile saline is probably the vehicle most frequently used in experiments involving intracerebral injections. Some drugs, however, are slightly soluble in water and DMSO/ water solutions have been used as solvents in experiments involving centrally acting compounds. For example, Bianchin et al. (5) employed a $25 \%(\mathrm{v} / \mathrm{v})$ DMSO solution to dissolve and inject the non-NMDA antagonist CNQX into the hippocampus and/or amygdala. Our results showed that $10 \%$ DMSO (v/v) significantly increased the number of entries into open or enclosed arms of the elevated plus maze compared to saline, and tended to do the same for the enclosed arms compared to Tween-80. Rodents exposed to the elevated plus maze naturally avoid the open arms of the maze, probably because they cannot engage in thigmotactic behavior (9). The elevated plus maze test, due to its simplicity and ethological basis, has been widely used to determine drug effects on anxiety after systemic or intracerebral injections $(1,3,10,11)$. Changes in the number of both open and enclosed arm entries are often interpreted to reflect general changes in exploratory activity $(10,11)$. The results, therefore, suggest that the intraDPAG administration of DMSO at $10 \%$ concentration is able to increase exploratory

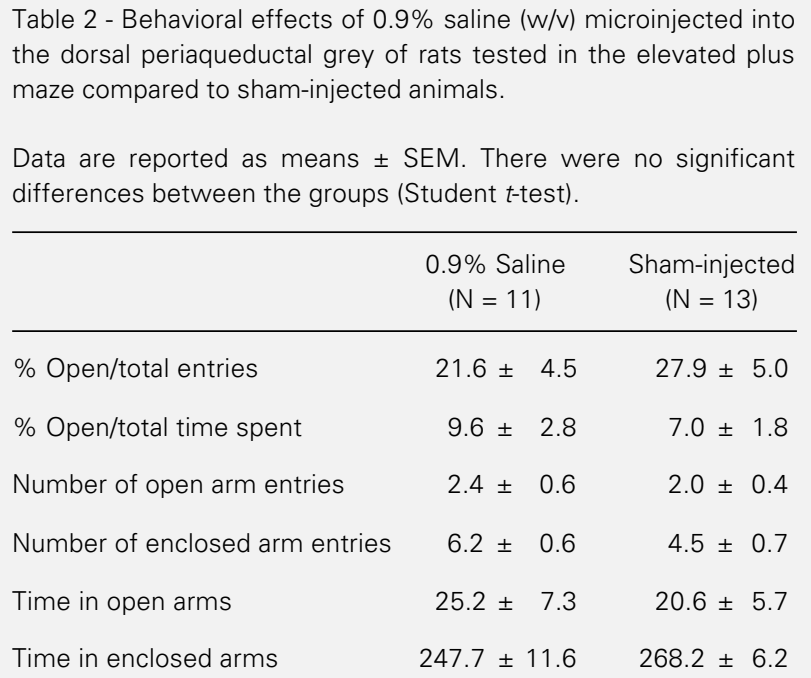

activity in the plus maze. Recently, Castro et al. (6), who investigated the effect of several vehicles, including DSMO, on mice locomotor activity, showed that DMSO at concentrations of 32 or $64 \%$ significantly decreased exploratory activity. These results, however, were obtained after systemic administration and are difficult to compare with results obtained after the administration into discrete brain regions. Electrophysiological studies showed that DMSO, at a concentration similar to that used in the present study $(8.3 \%, \mathrm{v} / \mathrm{v})$, depresses the increase 
in membrane permeability induced by acetylcholine, glutamate and GABA in Aplysia ganglion cells (12). It remains to be investigated if these effects are related to the behavioral changes found in the present study.

Our second experiment also showed no difference between rats injected with $0.9 \%$ sterile saline and sham-injected animals. This result suggests that $0.9 \%$ saline is a suitable vehicle for experiments using intra-DPAG injections. The saline-injected group in the second experiment showed greater plus maze exploration than the group in the first one. However, the two experiments were performed by different persons (M.G.M. vs J.C.L., respectively) at distinct times. Our data suggest that, as noted in uncontrolled observations, factors other than the specific treatment tested may influence rat behavior in the elevated plus maze, and support the recommendation to run different groups in parallel when performing the elevated plus maze.

In conclusion, our data showed that intraDPAG injection of some commonly used vehicles such as aqueous DMSO, saline or Tween-80 in water may differentially affect the exploratory activity of rats exposed to the elevated plus maze.

\section{Acknowledgment}

We thank J.C. de Aguiar for excellent technical support.

\section{References}

1. Graeff FG (1991). Neurotransmitters in the dorsal periaqueductal grey and animal models of anxiety. In: Briley M \& File SE (Editors), New Concepts in Anxiety. MacMillan Press, London, 288-312.

2. Guimarães FS, Carobrez AP, de Aguiar JC \& Graeff FG (1993). Anxiolytic effect in the elevated plus-maze of the NMDA receptor antagonist AP7 microinjected into the dorsal periaqueductal grey. Psychopharmacology, 103: 91-94.

3. Russo AS, Guimarães FS, de Aguiar JC \& Graeff FG (1993). Role of benzodiazepine receptors located in the dorsal periaqueductal grey of rats in anxiety. Psychopharmacology, 110: 198-202.

4. Routtenberg A (1973). Intracranial chemical injection and behavior: a critical review. Behavioral Biology, 7: 601-641.
5. Bianchin M, Walz R, Ruschel AC, Zanatta MS, da Silva RC, Bueno e Silva M, Paczko N, Medina JH \& Izquierdo I (1993). Memory expression is blocked by the infusion of CNOX into the hippocampus and/or the amygdala up to 20 days after training. Behavioral and Neural Biology, 59: 83-86.

6. Castro CA, Hogan JB, Benson KA, Shehata CW \& Landauer MR (1995). Behavioral effects of vehicles: DMSO, ethanol, Tween-20, Tween-80, and emulphor620. Pharmacology, Biochemistry and Behavior, 50: 521-526.

7. Paxinos G \& Watson C (1986). The Rat Brain in Stereotaxic Coordinates. 2nd edn. Academic Press, San Diego.

8. Elliot KAC \& Jasper HH (1949). Physiological salt solutions for brain surgery studies of local $\mathrm{pH}$ and pial vessel reactions to buffered and unbuffered isotonic saline. Journal of Neurosurgery, 6: 140-156.
9. Treit D, Menard J \& Royan C (1993). Anxiogenic stimuli in the elevated plusmaze. Pharmacology, Biochemistry and Behavior, 44: 463-469.

10. File SE (1992). Behavioural detection of anxiolytic action. In: Elliott JM, Heal DJ \& Marsden CA (Editors), Experimental Approaches to Anxiety and Depression. John Wiley \& Sons, New York, 25-44.

11. Pellow S, Chopin P, File SE \& Briley $M$ (1985). Validation of open:closed arm entries in an elevated plus-maze as a measure of anxiety in the rat. Journal of Neuroscience Methods, 14: 149-167.

12. Sawada M \& Sato M (1975). The effect of dimethyl sulfoxide on the neuronal excitability and cholinergic transmission in Aplysia ganglion cells. Annals of the New York Academy of Sciences, 243: 337-357. 